\title{
Serological evidence of hepatitis $E$ virus infection in pigs and jaundice among pig handlers in Bangladesh
}

Haider, Najmul; Khan, M. S. U.; Hossain, M. B. ; Sazzad, H. M. S. ; Rahman, M. Z.; Ahmed, F.; Zeidner, N. S.

Published in:

Zoonoses and Public Health

Link to article, DOI:

10.1111/zph.12372

Publication date:

2017

Document Version

Peer reviewed version

Link back to DTU Orbit

Citation (APA):

Haider, N., Khan, M. S. U., Hossain, M. B., Sazzad, H. M. S., Rahman, M. Z., Ahmed, F., \& Zeidner, N. S. (2017). Serological evidence of hepatitis $E$ virus infection in pigs and jaundice among pig handlers in Bangladesh. Zoonoses and Public Health, 64(7), 572-577. https://doi.org/10.1111/zph.12372

\section{General rights}

Copyright and moral rights for the publications made accessible in the public portal are retained by the authors and/or other copyright owners and it is a condition of accessing publications that users recognise and abide by the legal requirements associated with these rights.

- Users may download and print one copy of any publication from the public portal for the purpose of private study or research.

- You may not further distribute the material or use it for any profit-making activity or commercial gain

- You may freely distribute the URL identifying the publication in the public portal 
Serological evidence of Hepatitis E Virus infection in pigs and jaundice among pig handlers in Bangladesh

Najmul Haider ${ }^{1,3,4}$ M. Salah Uddin Khan ${ }^{1,2}$, M. Belal Hossain ${ }^{1}$, Hossain M S Sazzad ${ }^{1}$, M. Ziaur Rahman $^{1}$, Firoz Ahmed ${ }^{1}$, Nordin S. Zeidner ${ }^{1}$

${ }^{1}$ International Centre for Diarrhoeal Diseases Research, Bangladesh (icddr,b), Dhaka, Bangladesh

${ }^{2}$ Universirty of Guelph, Guelph, Canada

${ }^{3}$ American International University-Bangladesh, Dhaka, Bangladesh

${ }^{4}$ Section for Diagnostics and Scientific Advice, National Veterinary Institute, Technical University of Denmark, Copenhagen, Denmark

Key words: Hepatitis E Virus, pigs, pork, pig handlers, jaundice, Bangladesh, Zoonotic HEV

Hepatitis E Virus (HEV) is the most common cause of viral hepatitis in humans. Pigs may act as a reservoir of HEV and pig-handlers were frequently identified with a higher prevalence of antibodies to HEV. The objectives of this study were to identify evidence of HEV infection in pigs, and compare the history of jaundice between pig handlers and people not exposed to pigs and pork.

Blood and fecal samples were collected from 100 pigs derived from three slaughterhouses in the Gazipur district of Bangladesh from January to June, 2011. We also interviewed 200 pig handlers and 250 non-exposed people who did not eat pork or handled pigs in the past 2 years. We tested the pig sera for HEV-specific antibodies using a competitive ELISA and pig fecal samples for HEV RNA using real time RT-PCR.

Out of 100 pig sera, 82\% (n=82) had detectable antibody against HEV. Of the 200 pig handlers, 28\% (56/200) demonstrated jaundice within the past two years, whereas only $17 \%(43 / 250)$ of controls had a history of jaundice $(\mathrm{p}<0.05)$. Compared to non-exposed people, those who slaughtered pigs (31\% vs. 15\%, p<0.001), reared pigs (37\% vs. 20\%, $\mathrm{p}<0.001$ ), butchered pigs (35\% vs. 19\%, $\mathrm{p}<0.001$ ), or were involved in pork transportation (28\% vs. $13 \%, \mathrm{p}<0.001$ ) were more likely to be affected with jaundice in the preceding two years. In 
32 multivariate logistic regression analysis, exposure to pigs (Odds ratio [OR]: 2.2, 95\% CI: 1.2-

33 3.9) and age (OR: 0.97, 95\% CI: 0.95-0.99) was significantly associated with jaundice in the past

34 two years.

35 Pigs in Bangladesh demonstrated evidence of HEV infection and a history of jaundice was

36 significantly more frequent in pig handlers. Identifying and genotyping HEV in pigs and pig

37 handlers may provide further evidence of the pig's role in zoonotic HEV transmission in

38 Bangladesh.

\section{$41 \quad$ Impacts}

- Pigs may act as a reservoir of Hepatitis E Virus (HEV) and pig-handlers were frequently identified with a higher prevalence of antibodies to HEV.

- We found that $82 \%$ of pigs in Bangladesh had detectable antibody against HEV.

- Compared to non-exposed, people those who have exposure to pigs (slaughtered pigs, reared pigs, or butchered pigs), were more likely to be affected with jaundice in a two year period preceding our study. 
Introduction

Hepatitis E Virus (HEV) is the most common cause of viral hepatitis globally (Labrique et al., 1999). HEV has four major genotypes (1, 2, 3, and 4) and all of them infect humans. Genotypes 1 and 2 are transmissible among humans only, whereas Genotypes 3 and 4 are zoonotic in nature and prevalent both in low and high-income countries (Cooper et al., 2005, Meng et al., 2002). Antibodies against HEV have been found in a wide variety of domestic animals, including pigs (Zhang et al., 2008). As has been demonstrated in other parts of the world, HEV is endemic among pigs in those regions surrounding Bangladesh, particularly within India, Nepal, China, and Japan (Clayson et al., 1995, Takahashi et al., 2003, Shukla et al., 2007, Vivek \& Kang, 2011, Zhang et al., 2008). However, HEV in pigs had not been previously reported in Bangladesh.

Acute HEV infection in humans is associated with clinical features that include jaundice, dark colored urine, fatigue, vomiting, and abdominal pain (Ryder \& Beckingham, 2001). Jaundice is a common clinical feature for any viral hepatitis and is considered as an important clinical manifestation and the most probable indicator of HEV infection (Gupta et al., 2011). More than one third of hospitalized jaundice patients are associated with underlying HEV infection (Gupta et al., 2011). Animal handlers, such as farmers, have been shown to be at increased risk of HEV infection (Lee et al., 2013). A recent study conducted in India found 94\% of pig handlers had antibodies against HEV, a rate higher than rural (59\%) and urban (73\%) controls (Vivek \& Kang, 2011). Similar findings were reported from China, Thailand and the USA (Meng, 2009, Meng, 2010, Cooper et al., 2005).

Although predominantly a Muslim country, in Bangladesh there is a significant number of Christian households that rear pigs for personal consumption (Nahar et al., 2013). The pig population in Bangladesh is estimated to be approximately eight million (Khan et al., 2014). There are some regions where pig rearing is popular, including the districts of Rajshahi, Chapai Nawabganj, Mymensingh, Noagan, Gazipur and Tangail. Moreover, there is a government pig farm in Rangamati (Islam et al., 2006, Khan et al., 2014, Nahar et al., 2013). HEV has been a leading cause of hepatitis in Bangladesh and testing 
whether zoonotic transmission of HEV occurs in Bangladesh is important in this regard. We conducted this study to identify evidence of HEV infection in pigs and to compare the history of jaundice between pig handlers and people not exposed to pigs and pork.

\section{Methods}

Pig HEV serology

From January to June 2011, we collected blood and fecal samples from pigs slaughtered in three abattoirs within the Gazipur district of Bangladesh. We recorded demographic information including age (in months), sex, breed (indigenous vs crossbred), and herd size of the pigs (in number). Blood samples were kept at room temperature for 30 minutes and serum was separated by centrifugation and preserved at $2-8^{\circ} \mathrm{C}$ in a cold box before being transferred to icddr,b’s animal laboratory where they were stored at $-20^{\circ} \mathrm{C}$ until testing.

\section{Anti HEV serology and testing for HEV RNA}

Anti-HEV antibodies were detected by commercial HEV ELISA kit (MP Biomedicals, Singapore) according to the manufacturer's protocol (Kaufmann et al., 2011). Initially, reactive samples were re-tested and those with repeated reactive results were considered positive. According to the manufacturer, the kit possesses $97 \%$ sensitivity and $98 \%$ specificity for the detection of HEV antibodies. The kit is based on a double-antigen sandwich ELISA, which permits detection of all groups of immunoglobulin (IgG, IgA, IgM) in all animal species (Andraud et al., 2014). We then tested the sera and fecal samples of all 100 pigs by real time reverse transcriptase polymerase chain reaction (RT-PCR) as described previously (Gyarmati et al., 2007).

\section{Human jaundice and exposure to pigs}

We enrolled people working with pigs or pork-processing from the regions primarily known for pig rearing in Bangladesh (Rajshahi, Chapai Nawabganj) (Khan et al., 2014), as well as a pig slaughter house in Gazipur (Haider et al., 2012). We defined a person as a pig or pork handler who had been involved with any one of the following activities for the past two years: rearing 
pigs, slaughtering pigs, butchering pigs, selling pork, transporting pork or eating pork. We then enrolled non-pig or pork-exposed control individuals from the same geographical regions and confirmed that they were not involved in any of the activities mentioned above within the past two years.

We defined persons as jaundiced when they reported yellowish discoloration of the sclera as well as dark or yellow colored urine, or any person having laboratory diagnosis of increased bilirubin levels (>3mg/dl) within the past two years (Gupta et al., 2011). All enrolled individuals were interviewed regarding demographic information, exposure to pigs and pork, and a history of jaundice through a structured questionnaire.

\section{Sample size estimation:}

We estimated the sample size necessary to detect a significant difference between exposed and non-exposed human subjects enrolled in this study. Considering a hypothetical proportion of $20 \%$ jaundiced people in the pig exposed group and 10\% jaundiced people in the non-exposed group, with a 95\% confidence interval and $80 \%$ power, our estimated sample size was 286 for each group. We were able to enroll 250 people in non-exposed groups, 200 people in the exposed group due to lack of resources and time constraints and, most importantly, somewhat fewer pig raisers within a predominantly Muslim country. For studying HEV sero-prevalence in pigs, we considered a 60\% seroprevalence of HEV antibodies in pigs based on the published literature of neighboring countries (Clayson et al., 1995, Shukla et al., 2007, Zhang et al., 2008) and estimated that 270 pigs should be enrolled (AusVet: Animal Health Services, 2016) . However, we were only able to enroll 100 pigs because of limited resources as well as the constraints listed above.

\section{Data analysis}

We stratified the sero-prevalence of HEV in pigs by age, sex, breed, and herd size. We classified the human exposure group into two primary groups: exposure to pigs and exposure to pork. The people who were primarily involved with rearing pigs, slaughtering pigs and butchering pigs were grouped as "exposure to pigs". In contrast, those who 
exclusively ate pork, worked as salesmen, or who were involved in transporting pork were classified as “exposure to pork”. We used the chi-square or Fisher's exact test to identify the association between people having jaundice with their exposure to pigs (rearing pigs, slaughtering pigs and butchering pigs) or pork (eating pork, working as salesmen, and transporting pork). We performed univariate and multivariate logistic regression analysis to identify significant risk factors for acquiring jaundice in the past two years.

\section{Ethical approval:}

The study was part of a study at American International University of Bangladesh and the study protocol was approved by the ethical committee of the university. All participants and pig owners provided oral consent before they were enrolled in the study.

\section{Results:}

Serum samples were collected from 100 pigs in three slaughterhouses located within the villages of Kaligonj sub-district of Gazipur district of Bangladesh. Although the slaughterhouse owners collected pigs from different districts of Bangladesh, the majority of pigs were brought from Barisal (33\%), Jessore (25\%), and Gazipur districts (14\%). Of the 100 pigs tested for HEV-specific antibodies, 82\% (82/100) had anti-HEV antibodies.

\section{Pig demography and HEV status}

Compared to the pigs that lacked HEV antibody, pigs with HEV antibody were older [21.5 months vs. 9.6 months, $\mathrm{p}<0.001$ ], were more likely to be raised in larger herds (mean herd size: 194 pigs, vs. 125 pigs, $\mathrm{p}=0.008$ ), were predominantly male (60\%, vs. 22\% p=0.004), and were more likely to be an indigenous breed (89\% vs. 39\%, p<0.001). No HEV RNA was detected from any fecal samples.

\section{Exposure to pigs and Jaundice history of pig handlers}

We enrolled 450 persons from 12 districts of Bangladesh: 200 were pig handlers and 250 were controls who never handled pigs or eat pork. Among 450 persons, 46\% $(n=206)$ were Christian, 40\% (n=181) were Muslim, and the rest $(14 \%)(n=63)$ were Hindu. Of the 
200 pig handlers, 28\% $(n=56)$ demonstrated jaundice within the past two years, whereas only $17 \%(n=43)$ of controls had a history of jaundice $(\mathrm{p}<0.05)$. The mean age of people having jaundice was 33.2 years compared to 37.6 years for controls $(\mathrm{p}<0.05)$.

People had different levels of exposure to pig and pork: 24\% $(n=107)$ were involved in rearing pigs, $18 \%(n=82)$ worked at a slaughter house, $23 \%(103)$ were involved in butchering pigs, $17 \%(n=77)$ were involved in transportation of pigs, $16 \%(n=16)$ were involved in selling pork, and 50\% $(\mathrm{n}=226)$ had eaten pork within the past two years. The people who were exposed to pigs (OR: 2.2, 95\% CI: 1.2-3.9) were more likely to be affected with jaundice whereas older aged people demonstrated a low risk of having jaundice (OR: 0.97, 95\% CI: 0.95- 0.99) compared to younger adults.

\section{Discussion}

This study demonstrated that pigs in Bangladesh have been exposed to the Hepatitis E Virus. Anti-HEV antibodies have been demonstrated among pigs in several HEV-endemic and nonendemic countries, including India, China, Nepal, Taiwan, USA and Canada (Vivek \& Kang, 2011, Zhang et al., 2008, Zhang et al., 2009, Zhuang, 1991, Clayson et al., 1995, Wu et al., 2002, Meng et al., 2002, Dalton et al., 2008, Yoo et al., 2001). The prevalence of anti-HEV antibodies among pigs in this study was similar to other endemic countries in this region including China (83\%) (Zhang et al., 2008), Nepal (85\%) (Clayson et al., 1995) and India (94\%) (Shukla et al., 2007). The pigs enrolled in the study were reared locally within the country, indicating that these pigs were probably exposed to a locally circulating HEV virus.

We found a variation of anti-HEV antibody status of pigs according to age, sex, breed and herd size. The differences in ages may be indicative to a cumulative life-time exposure to an as yet an unknown environmental source which is consistent with other reports (Meng, 1997). Pigs sampled from larger herds had HEV antibody more frequently than the smaller herds could be due to cumulative exposure to larger number of animals, and is consistent with other studies (Yoo et al., 2001). The differences in HEV antibodies in breed might be associated with the differences in rearing systems as well as herd size 
because cross bred pigs are reared mostly in small scale farming systems and indigenous breeds are primarily reared in backyard farms (Khan et al., 2014). The reasons for the differences in the breed as well as sex should be explored in future studies.

Our study findings demonstrated that people exposed to pigs had a significantly higher risk of jaundice in Bangladesh. A recent study showed that 19 to 25\% of all maternal deaths and 7 to $13 \%$ of all neonatal deaths in Bangladesh were associated with jaundice in pregnant women (Gurley et al., 2012). In previous studies, 58\% of deaths in pregnant women with ongoing acute liver disease were associated with HEV infection (Gurley et al., 2012). In Bangladesh, 30-60\% of the acute viral hepatitis patient has an underlying HEV etiology (Labrique et al., 2009). Recently, a number of human HEV outbreaks in Bangladesh were associated with contaminated drinking water (Haque et al., 2015). However, there is little information available regarding the zoonotic transmission of HEV in human cases in Bangladesh.

Exposure to pigs and resultant jaundice makes biological sense because HEV is known to be transmitted by a fecal-oral route within animals species, from animals to humans in infectious body fluids, and from contaminated food or water sources to humans and other animals (Meng, 2009). Insufficient disposal and poor management of sewage and contamination of drinking and irrigation water was responsible for many HEV epidemics in developing countries (Fu et al., 2010). Thus people working in some activities with pigs would have greater risks of viral exposure. In contrast, people who are simply exposed to pork should have a minimal chance of live viral infection because the cultural norm in Bangladesh is to cook meat above boiling temperature sufficient to kill HEV (Barnaud et al., 2012). The fact that older people were seemingly protected could be due to their cumulative viral exposure to various agents of hepatitis, including HEV, which is supported by earlier studies (Dalton et al., 2011).

Although we did not detect HEV RNA in our samples, it should be noted that detection of HEV from pigs depends on several factors, including the age of the pigs. Previous studies have shown that pigs only shed virus between the ages of 2 to 4 months (Cooper et al., 2005) and infected piglets generally have only a transient viremia lasting for 1 to 2 weeks shedding virus in feces for 
227 about 3 to 7 weeks (Meng, 2009). Likewise, the serum samples we tested were collected only

228 from adult pigs which would explain why we did not detect any HEV RNA. Further exploration

229 into the circulating genotype of HEV in pigs in Bangladesh is important, as it could help target

230 specific interventions for human HEV infection from zoonotic and/or other environmental

231 sources.

232

233 Limitations:

234 We classified people as jaundice based on clinical history and laboratory results. In fact, most of 235 the enrolled patients could not show the laboratory results and therefore we had to rely on 236 clinical history. Clinical signs and their history are highly subjective and typically embraces 237 recall bias. Therefore, there is a chance of misclassification of the people classified as jaundice. 238 Although we could not rule this out, further studies with laboratory confirmation will allow us 239 better understanding the potential role of zoonotic HEV among jaundice or hepatitis patients in

240 Bangladesh. Too, there is potential risk that people in the non-pig exposed group are different by 241 a number of characteristics compared with those exposed to pigs. The difference could result 242 from other population level differences rather than exposure to pigs and pork. These might 243 include specific diets, which could be heavily influenced by religion and culture, and water 244 sources that are strongly influenced by income. However, detection of differences in occurrences 245 of jaundice makes biological sense and worth confirmation through future studies.

\section{Conclusion:}

248 This study provides evidence that pigs in Bangladesh are exposed to HEV. Presence of anti-

$249 \mathrm{HEV}$ antibodies in pigs has important implications for public health in Bangladesh since 250 people exposed to pigs had a significantly higher risk of jaundice. Identifying HEV genotypes in 251 pigs could shed light on the extent of zoonotic HEV transmission in Bangladesh and provide a 252 platform for public health intervention strategies. 
255 Acknowledgement: The authors express sincere gratitude to Stephen P Luby for reviewing this 256 manuscript. icddr,B acknowledges with gratitude the commitment of the Governments of

257 Bangladesh, Canada, Sweden, and the UK for providing core support.

258

259

260

Tables:

261

262 Table-1: Status of Hepatitis E Virus antibodies among pigs slaughtered in three slaughterhouses 263 in Kaligong sub-district of Gazipur district of Bangladesh, January -June, 2011.

264

265

Table-2: Univariate and multivariate logistic regression analysis on the factors associated 266 with jaundice of pig handlers and non-exposed people enrolled from different districts of 267 Bangladesh between January-June, 2011.

268 
271 Table-1: Status of Hepatitis E Virus antibodies among pigs slaughtered in three slaughterhouses

272 in Kaligong sub-district of Gazipur district of Bangladesh, January -June, 2011.

273

\begin{tabular}{|c|c|c|c|}
\hline & $\begin{array}{l}\text { HEV antibody } \\
\text { positive pigs } \\
\mathrm{N}=82 \\
\mathrm{n}(\%)\end{array}$ & $\begin{array}{l}\text { HEV } \\
\text { antibody } \\
\text { negative pigs } \\
\mathrm{N}=18 \\
\mathrm{n}(\%)\end{array}$ & P value \\
\hline Sex of the pigs - male (vs. female) & $49(60)$ & $4(22)$ & 0.004 \\
\hline $\begin{array}{l}\text { Breed of the pigs - indigenous (vs. cross } \\
\text { breed) }\end{array}$ & 73 (89) & $7(38)$ & $<0.001$ \\
\hline Mean number of pigs in herd & 193 & 125 & $<0.001$ \\
\hline Mean age of pigs (in months) & 21 & 10 & $<0.001$ \\
\hline
\end{tabular}

274

275 
Table-2: Univariate and multivariate logistic regression analysis on the factors associated with jaundice of pig handlers and non-exposed people enrolled from different districts of Bangladesh between January-June, 2011.

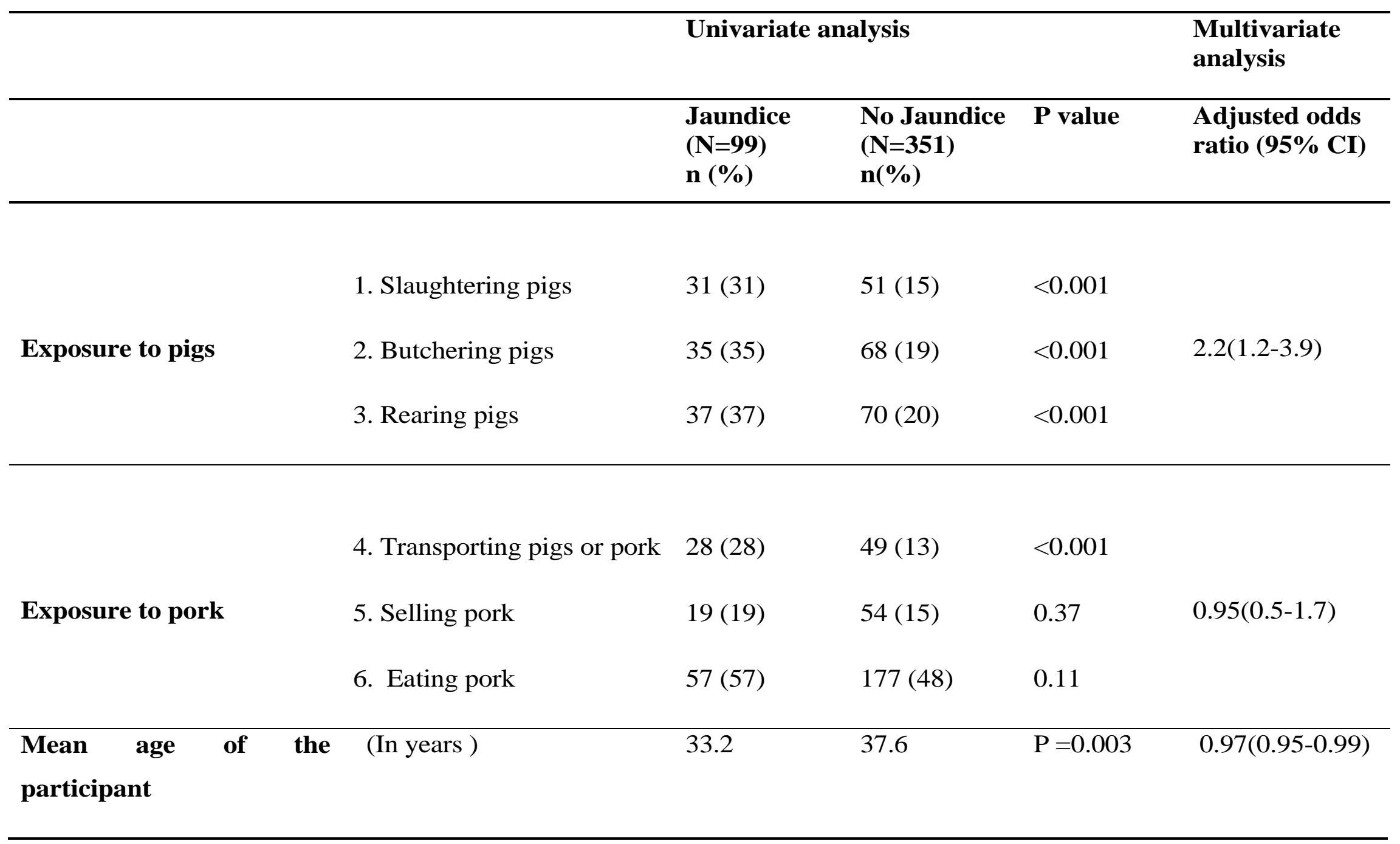




\section{References:}

Andraud, M., M. Casas, N. Pavio and N. Rose, 2014: Early-life hepatitis e infection in pigs: the importance of maternally-derived antibodies. PloS one, 9, e105527.

AusVet: Animal Health Services, 2016: Epi Tools - Sample size calculations: available at http://epitools.ausvet.com.au/content.php?page $=2$ Proportions $\& P 1=0.20 \& P 2=0.10 \&$ Conf $=0.95$ \&Power $=0.8 \&$ Ratio $=1 \&$ Tails $=2$.

Barnaud, E., S. Rogee, P. Garry, N. Rose and N. Pavio, 2012: Thermal inactivation of infectious hepatitis E virus in experimentally contaminated food. Applied and environmental microbiology, 78, 51535159.

Clayson, E. T., B. L. Innis, K. S. Myint, S. Narupiti, D. W. Vaughn, S. Giri, P. Ranabhat and M. P. Shrestha, 1995: Detection of hepatitis E virus infections among domestic swine in the Kathmandu Valley of Nepal. The American journal of tropical medicine and hygiene, 53, 228-232.

Cooper, K., F. F. Huang, L. Batista, C. D. Rayo, J. C. Bezanilla, T. E. Toth and X. J. Meng, 2005: Identification of genotype 3 hepatitis $E$ virus (HEV) in serum and fecal samples from pigs in Thailand and Mexico, where genotype 1 and $2 \mathrm{HEV}$ strains are prevalent in the respective human populations. Journal of clinical microbiology, 43, 1684-1688.

Dalton, H. R., R. Bendall, S. ljaz and M. Banks, 2008: Hepatitis E: an emerging infection in developed countries. Lancet Infect Dis, 8, 698-709.

Dalton, H. R., R. P. Bendall, M. Rashid, V. Ellis, R. Ali, R. Ramnarace, W. Stableforth, W. Headdon, R. Abbott, C. McLaughlin, E. Froment, K. J. Hall, N. P. Michell, P. Thatcher and W. E. Henley, 2011: Host risk factors and autochthonous hepatitis E infection. European journal of gastroenterology \& hepatology, 23, 1200-1205.

Fu, H., L. Li, Y. Zhu, L. Wang, J. Geng, Y. Chang, C. Xue, G. Du, Y. Li and H. Zhuang, 2010: Hepatitis E virus infection among animals and humans in Xinjiang, China: possibility of swine to human transmission of sporadic hepatitis $\mathrm{E}$ in an endemic area. The American journal of tropical medicine and hygiene, 82, 961-966.

Gupta, M., R. Patil, M. I. Khan and S. K. Gupta, 2011: Retrospective hospital based study of Infective causes of Jaundice in Tamilnadu, India. Calicut Medical Journal, 9, e4.

Gurley, E. S., A. K. Halder, P. K. Streatfield, H. M. Sazzad, T. M. Huda, M. J. Hossain and S. P. Luby, 2012: Estimating the burden of maternal and neonatal deaths associated with jaundice in Bangladesh: possible role of hepatitis E infection. Am J Public Health, 102, 2248-2254.

Gyarmati, P., N. Mohammed, H. Norder, J. Blomberg, S. Belak and F. Widen, 2007: Universal detection of hepatitis E virus by two real-time PCR assays: TaqMan and Primer-Probe Energy Transfer. Journal of virological methods, 146, 226-235.

Haider, N., M. A. Rahim, M. S. U. Khan, F. Ahmed, S. K. Paul, M. Z. Rahman, S. P. Luby and A. B. Mikolon, 2012: Serological evidence of Hepatitis E Virus in pigs in Bangladesh. International Journal of Infectious Diseases, 16, e451.

Haque, F., S. S. Banu, K. Ara, I. A. Chowdhury, S. A. Chowdhury, S. Kamili, M. Rahman and S. P. Luby, 2015: An outbreak of hepatitis $E$ in an urban area of Bangladesh. Journal of viral hepatitis, 22, 948-956.

Islam, A., S. Majumder, M. Anisuzzaman, A. Rabbi and M. H. Rahman, 2006: Helminthiasis in Pigs in Bangladesh in relation to Age and Management systems. Bangladesh Vet J 40, 27-32. 
Kaufmann, A., A. Kenfak-Foguena, C. Andre, G. Canellini, P. Burgisser, D. Moradpour, K. E. Darling and M. Cavassini, 2011: Hepatitis E virus seroprevalence among blood donors in southwest Switzerland. PloS one, 6, e21150.

Khan, S. U., H. Salje, A. Hannan, M. A. Islam, A. A. Bhuyan, M. A. Islam, M. Z. Rahman, N. Nahar, M. J. Hossain, S. P. Luby and E. S. Gurley, 2014: Dynamics of Japanese encephalitis virus transmission among pigs in Northwest Bangladesh and the potential impact of pig vaccination. PLoS neglected tropical diseases, 8, e3166.

Labrique, A. B., D. L. Thomas, S. K. Stoszek and K. E. Nelson, 1999: Hepatitis E: an emerging infectious disease. Epidemiol Rev, 21, 162-179.

Labrique, A. B., K. Zaman, Z. Hossain, P. Saha, M. Yunus, A. Hossain, J. Ticehurst and K. E. Nelson, 2009: Population seroprevalence of hepatitis $\mathrm{E}$ virus antibodies in rural Bangladesh. The American journal of tropical medicine and hygiene, 81, 875-881.

Lee, J. T., P. L. Shao, L. Y. Chang, N. S. Xia, P. J. Chen, C. Y. Lu and L. M. Huang, 2013: Seroprevalence of Hepatitis E Virus Infection among Swine Farmers and the General Population in Rural Taiwan. PloS one, 8, e67180.

Meng, X. J., 2009: Hepatitis E virus: animal reservoirs and zoonotic risk. Vet Microbiol, 140, 256-265.

Meng, X. J., 2010: Recent advances in Hepatitis E virus. Journal of viral hepatitis, 17, 153-161.

Meng, X. J., Purecell RH, Halbur PG, Lehman JR, Webb DM, Tsareva TS, Haynes JS, Thacker BJ, Emerson SU, , 1997: A Novel virus in Swine is closely related to human hepatitis E virus. . Proc. Natl Acad Sci, USA 94, 9860-9865.

Meng, X. J., B. Wiseman, F. Elvinger, D. K. Guenette, T. E. Toth, R. E. Engle, S. U. Emerson and R. H. Purcell, 2002: Prevalence of antibodies to hepatitis E virus in veterinarians working with swine and in normal blood donors in the United States and other countries. Journal of clinical microbiology, 40, 117-122.

Nahar, N., M. Uddin, R. A. Sarkar, E. S. Gurley, M. S. Uddin Khan, M. J. Hossain, R. Sultana and S. P. Luby, 2013: Exploring pig raising in Bangladesh: implications for public health interventions. Veterinaria italiana, 49, 7-17.

Ryder, S. D. and I. J. Beckingham, 2001: ABC of diseases of liver, pancreas, and biliary system: Acute hepatitis. Bmj, 322, 151-153.

Shukla, P., U. K. Chauhan, S. Naik, D. Anderson and R. Aggarwal, 2007: Hepatitis E virus infection among animals in northern India: an unlikely source of human disease. Journal of viral hepatitis, 14, 310-317.

Takahashi, M., T. Nishizawa and H. Okamoto, 2003: Identification of a genotype III swine hepatitis E virus that was isolated from a Japanese pig born in 1990 and that is most closely related to Japanese isolates of human hepatitis E virus. Journal of clinical microbiology, 41, 1342-1343.

Vivek, R. and G. Kang, 2011: Hepatitis e virus infections in Swine and Swine handlers in vellore, southern India. The American journal of tropical medicine and hygiene, 84, 647-649.

Wu, J. C., C. M. Chen, T. Y. Chiang, W. H. Tsai, W. J. Jeng, I. J. Sheen, C. C. Lin and X. J. Meng, 2002: Spread of hepatitis E virus among different-aged pigs: two-year survey in Taiwan. J Med Virol, 66, 488-492.

Yoo, D., P. Willson, Y. Pei, M. A. Hayes, A. Deckert, C. E. Dewey, R. M. Friendship, Y. Yoon, M. Gottschalk, C. Yason and A. Giulivi, 2001: Prevalence of hepatitis E virus antibodies in Canadian swine herds and identification of a novel variant of swine hepatitis E virus. Clin Diagn Lab Immunol, 8, 12131219.

Zhang, W., Q. Shen, J. Mou, G. Gong, Z. Yang, L. Cui, J. Zhu, G. Ju and X. Hua, 2008: Hepatitis E virus infection among domestic animals in eastern China. Zoonoses Public Health, 55, 291-298. 
Zhang, W., S. Yang, L. Ren, Q. Shen, L. Cui, K. Fan, F. Huang, Y. Kang, T. Shan, J. Wei, H. Xiu, Y. Lou, J. Liu, Z. Yang, J. Zhu and X. Hua, 2009: Hepatitis E virus infection in central China reveals no evidence of cross-species transmission between human and swine in this area. PloS one, 4, e8156.

Zhuang, H., X. Y. Cao, C. B. Liu, and G. M. Wang, 1991: Enterically transmitted non-A, non-B hepatitis in China. In: Shikata, T., Purcell, R. H., and T. Uchida (eds), Viral Hepa-titis C, D, and E, pp. 277-285. Medica, Amsterdam - New York - Oxford. 